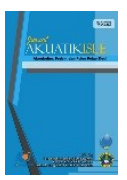

Artikel Penelitian 圆

\title{
Tingkat pemanfaatan ikan delah (Caesio teres) pada Perairan Mapur yang didaratkan di Desa Kelong, Kecamatan Bintan Pesisir, Kabupaten Bintan, Indonesia
}

\section{Utilization Rate of Yellow and blueback fusilier (Caesio teres) at Mapur Waters this fish landing on Kelong Village, Bintan coastal, Bintan Regency, Indonesia}

\author{
Rapella Desiani, Susiana ${ }^{\circledR}$, Febrianti Lestari \\ Department of Aquatic Resources Management, Faculty of Fisheries and Marine Sciences, Raja Ali Haji Maritime University. Jln. Politeknik \\ Senggarang, Tanjung Pinang, Kepulauan Riau 29111, Indonesia.
}

\section{■ Info Artikel:}

Diterima: 29 Juli 2019

Disetujui: 04 November 2019

Dipublikasi: 07 November 2019

\section{@eyword:}

Yellow and blueback fusilier; Mapur waters;

Landed;

Utilization Rate;

MSY;

$J T B$

\section{$\checkmark$ Correspondence:}

Susiana

Program Studi Manajemen Sumberdaya Perairan, Universitas Maritim Raja Ali Haji, Jln Politeknik Senggarang, Tanjung Pinang, Indonesia 29111

Email:susiana@umrah.ac.id

\begin{abstract}
ABSTRAK. Perairan Mapur terdapat berbagai jenis ikan yang ditangkap salah satunya adalah ikan delah. Ikan delah merupkan salah satu hasil tangkapan yang bernilai ekonomis tinggi. Nilai ekonomis yang tinggi ini tentunya dapat mendorong peningkatan penangkapan ikan delah dan dapat mempengaruhi populasinya. Penelitian ini dilaksanakan pada bulan Agustus 2018 sampai Juli 2019 ditempat pendaratan Desa Kelong. Alat yang digunakan yaitu alat tulis, kamera dan bahan yang digunakan adalah ikan delah sebagai objek penelitian. Tujuan dari penelitian ini adalah untuk mengetahui potensi lestari maksimum (MSY, tingkat dan upaya pemanfaatan, serta jumlah yang diperbolehkan (JTB) dalam penangkapan ikan delah Pada Perairan Mapur yang Didaratkan di Desa Kelong. Penelitian ini menggunakan metode survei dengan pengambilan data primer menggunakan wawancara nelayan langsung dan data sekunder terdiri dari dokumen dan literatur yang mendukung. Dari hasil penelitian didapatkan nilai potensial MSY sebesar 787,067 kg/unit dengan upaya optimum (fopt) 1.280 unit belum melebihi batas dengan kata lain belum overfishing. Tingkat pemanfaatan ikan delah yaitu $42 \%$ dikatagorikan sedang, sehingga jika dilakukan penambahan upaya masih memungkinkan untuk mengoptimalkan hasil tangkapan, tetapi tetap dikontrol. Dan jumlah yang diperbolehkan JTB ikan delah sebesar yaitu 629,65 kg/unit, bahwa penangkapan ikan delah masih bisa ditingkatkan untuk mendapatkan hasil yang optimal, tetapi tidak melebihi batas yang ditentukan.
\end{abstract}

ABSTRACT. The Mapur waters contain various kinds of fish caught in one of them is Yellow and blueback fusilier. Yellow and blueback fusilier is one of the catches of high economic valued. High economic value can certainly boost the Yellow and blueback fusilier and can affect the population. The research was conducted from August 2018 to July 2019 at this fish landing on Kelong Village. The tools used are stationery, cameras and materials used are fish as a research object. The aims of this research was to determine the Maximume Sustainable Yield (MSY), rate and effort of utilization, and the amount allowed to catch (JTB) of Yellow and blueback fusilier in Mapur waters landing this on Kelong Village. This research used survey method with primary data retrieval using live fishermen interviews and secondary data consists of document or literature that supports the research. The result of this research is the potential value of MSY is $787,067 \mathrm{~kg} / \mathrm{unit}$ whit the optimum effort (f opt) 1.280 unit/ month not over the limit in other words yet overfishing. The utilization rate of Yellow and blueback fusilier $42 \%$ medium level overall, and so if increased efforts are still possible to optimize the haul, but still controlled. And amount allowed to catch value Yellow and blueback fusilier is $629.65 \mathrm{~kg} / \mathrm{unit}$, that Yellow and blueback fusilier can still be improved for optimal results, but not beyond the determined limits.

Copyright@ November 2019 Desiani, R., Susiana \& Lestari, F. Under Licence a Creative Commons Attribution-ShareAlike 4.0 International License

\section{Pendahuluan}

Luas wilayah Kecamatan Bintan Pesisir $\pm 2.174 \mathrm{~km}$ terdiri dari daratan $\pm 234 \mathrm{~km}^{2}$ dan Lautan $\pm 1.940 \mathrm{~km}^{2}$ (Anonim, 2017). Luas daratan dari Kecamatan Bintan Pesisir hanya $11 \%$ dari total luas wilayah seluruhnya. Jumlah pulau-pulau yang ada di Kecamatan Bintan Pesisir berjumlah 54 pulau, yang terdiri dari pulau-pulau yang berpenduduk maupun tidak berpenduduk. Adapun pulau yang sudah berpenduduk sebesar 15 pulau, sedangkan pulau yang belum berpenduduk sebesar 39 pulau, sedangkan jumlah kampung yang ada di Kecamatan Bintan Pesisir sebanyak 20 (Anonim, 2017).

Desa Kelong adalah daerah ini merupakan daerah dimana nelayan mendaratkan ikan hasil tangkapan dan menampung hasil tangkapan ikan yang didapatkan. Salah 
satunya adalah ikan delah. Ikan delah salah satu jenis ikan target yang bernilai ekonomi (pasar) tinggi berdasarkan hasil wawancara senilai kisaran harga Rp.45.000,- sampai Rp.60.000,- dan harga ikan ekspor senilai Rp.60.000,- sampai Rp.90.000,- hasil dari olahan dan ikan delah juga dijadikan ikan yang olahannya ada di Desa Kelong, dan ikan yang permintaan pasar ekspor dan ikan delah juga dijadikan ikan yang olahannya ada di Desa Kelong, dengan tidak hanya dijual langsung tetapi juga dijual hanya dagingnya saja (fillet), setelah olah ini maka harga pasarannya juga menjadi naik dan akan menambah pendapatan masyarakat Desa Kelong.

Dalam upaya menjaga keberadaan stok perikanan perlu adanya pengelolaan dalam menjaga aktivitas kegiatan produksi serta pelestarian keanekaragaman hayati sumberdaya perikanan. Penangkapan ikan Delah di Desa Kelong ini yang masih bersifat open access (terbuka bagi setiap nelayan), dikhawatirkan dapat menyebabkan penangkapan berlebih (overfishing). Salah satu cara untuk mendukung pengelolaan perikanan yang berkelanjutan yaitu dengan mengetahui potensi lestari (MSY).

Desa Kelong adalah salah satu pulau yang ada di Kecamatan Bintan Pesisir, Kabupaten Bintan. Secara geografis, Pulau Kelong terletak antara 0050'17.00" U 104038'52.000" T (Direktori Pulau-Pulau Kecil Indonesia, 2012) dengan luas keseluruhan $\pm 627 \mathrm{~km}^{2}$. Luas daratan sebesar $\pm 57 \mathrm{~km}^{2}$, dan luas lautan $570 \mathrm{~km}^{2}$. Desa Kelong memiliki kondisi sumberdaya pesisir dan laut yang sangat berlimpah dikarenakan lautan lebih luas dibandingkan daratannya, dengan sebagian besar penduduknya hampir bekerja sebagai nelayan. Berdasarkan informasi dari profil Desa Kelong memiliki potensi wilayah yaitu potensi kelautan dan perikanan serta potensi perekonomian masyarakat yang perlu dikembangkan melalui UKM (Unit Kegiatan Masyarakat), perkreditan dan kegiatan ekonomi mikro lainnya, dan juga adanya pemanfaatan ekspor daging ikan delah yang dimana harga pasaranya lebih tinggi (Anonim, 2017).

Ikan delah adalah salah satu jenis ikan target yang bernilai ekonomi (pasar) tinggi berdasarkan hasil wawancara senilai kisaran harga Rp.45.000,- sampai Rp.60.000,- dan harga ikan ekspor senilai Rp.60.000,- sampai Rp.90.000,- hasil dari olahan dan ikan delah juga dijadikan ikan yang olahannya ada di Desa Kelong, dengan tidak hanya dijual langsung tetapi juga dijual hanya dagingnya saja (fillet), setelah olah ini maka harga pasarannya juga menjadi naik dan akan menambah pendapatan masyarakat Desa Kelong.

Dalam upaya menjaga keberadaan stok perikanan perlu adanya pengelolaan dalam menjaga aktivitas kegiatan produksi serta pelestarian keanekaragaman hayati sumberdaya perikanan. Penangkapan ikan Delah di Desa Kelong ini yang masih bersifat open access (terbuka bagi setiap nelayan), dikhawatirkan dapat menyebabkan penangkapan berlebih (overfishing). Salah satu upaya untuk mendukung pengelolaan perikanan berkelanjutan yaitu dengan mengetahui potensi lestari (MSY, maximum sustainable yield). Penelitian ini dilakukan dalam rangka untuk mengetahui tingkat pemanfaatan ikan delah dan jumlah tangkapan yang diperboleh (JTB) agar sumberdaya ikan delah tetap lestari tanpa merusak populasinya.

Penelitian bertujuan untuk menganalisis tingkat produksi lestari atau Maximum Sustainable Yield(MSY) ikan delah (Caesio teres) pada Perairan Mapur yang didaratkan di Desa Kelong meliputi produksi, tingkat pemanfaatan, dan jumlah tangkapan. Penelitian ini diharapkan memberikan informasi MSY dan upaya optimum (f optimum) sebagai bahan informasi pengelolaan ikan delah pada Perairan Mapur Kabupaten Bintan.

\section{Bahan dan Metode}

\subsection{Waktu dan Tempat}

Penelitian dilaksanakan pada bulan Agustus 2018 sampai bulan Juli 2019, berlokasi pendaratkan ikan di Desa Kelong Kecamatan Bintan Pesisir Kabupaten Bintan. Daerah ini merupakan daerah dimana nelayan mendaratkan ikan hasil tangkapan dan menampung hasil tangkapan ikan yang didapatkan. Peta lokasi penelitian disajikan pada Gambar 1.

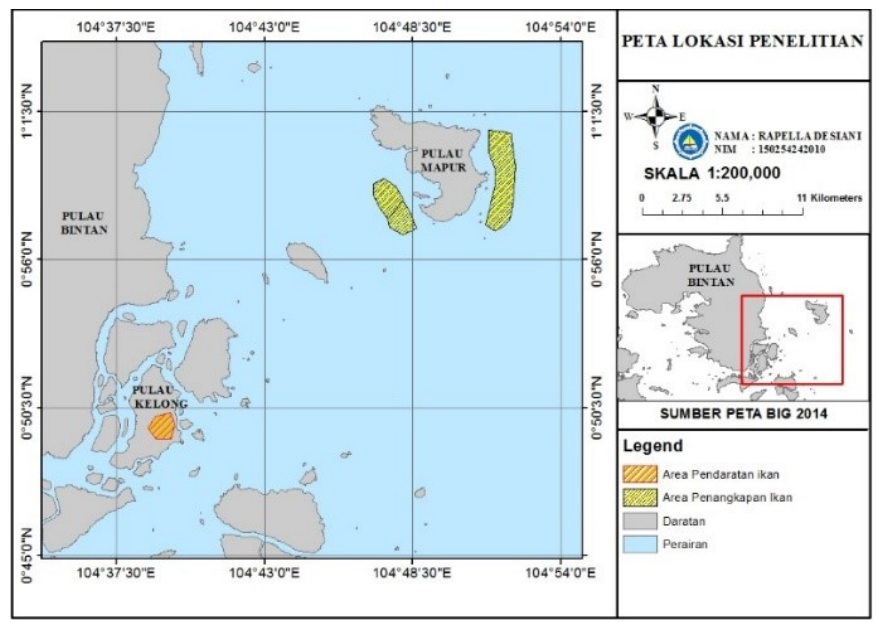

Gambar 1. Peta Lokasi Penelitian.

\subsection{Alat dan Bahan}

Alat yang digunakan pada penelitian ini yaitu alat tulis untuk mencatat data yang diambil dari lokasi penelitian dan kamera untuk dokumentasi. Sedangkan bahan yang digunakan yaitu ikan delah sebagai objek penelitian.

\subsection{Metode Penelitian}

Metode yang digunakan dalam penelitian ini yaitu analisis deskriptif dengan menggunakan metode survei data atau sensus. Sensus adalah pengumpulan data yang meliputi seluruh populasi yang diinginkan.

Data-data diperoleh melalui metode survey dan observasi langsung dilapangan. Dimana data yang diperoleh meliputi data primer dan data sekunder adalah sebagai berikut:

1. Data primer dilakukan dengan cara mewawancarai nelayan di Desa Kelong. Informasi yang diperoleh dari hasil wawancara berupa data kegiatan operasi penangkapan ikan, serta hasil tangkapan ikan yang kalkulasi perbulan.

2. Data Sekunder, merupakan data berkala (time series) hasil tangkapan dan upaya penangkapan dari bulan Agustus 2018 sampai April 2019 di Desa Kelong. Selain itu pengumpulan data sekunder juga akan dilakukan penelusuran pustaka dan hasil-hasil penelitian yang telah dilakukan pada berbagai instansi pemerintah. 


\subsection{Teknik Pengumpulan Data}

Penelitian ini menggunakan metode teknik survei lapangan, dimana pengambilan data dilakukan secara langsung di lapangan. Lokasi penelitian yaitu di Gudang Pendaratan Ikan di Desa Kelong Kecamatan Bintan Pesisir Kabupaten Bintan. Pengambilan data yaitu dengan melakukan pengamatan langsung dilokasi penelitian dengan mencatat berat hasil tangkapan $(\mathrm{kg})$, alat, dan armada tangkap, jumlah ABK (anak buah kapal) dalam operasi penangkapan ikan delah serta melakukan wawancara langsung dengan nelayan yang bekerja di gudang penampung ikan di Desa Kelong Kecamatan Bintan Pesisir Kabupaten Bintan.

\subsection{Analisis Data}

\subsubsection{Catch Unit Per Effort (CPUE)}

Perhitungan jumlah hasil tangkapan ikan delah, Menurut Mayu et al. (2018), rumus yang digunakan adalah sebagai berikut:

$$
\text { CPUE } i=\frac{\text { Catch } i}{\text { Effort } i}
$$

Keterangan: CPUE $\mathrm{i}=$ hasil tangkapan per satuan upaya penangkapan dalam bulan ke $1,2,3, . . \mathrm{n}$; Catch $\mathrm{i}=$ hasil tangkapan dalam bulan ke 1,2,3,..n; Effort $\mathrm{i}$ = upaya penangkapan dalam bulan ke $1,2,3, . . n$.

\subsubsection{Nilai Potensi Lestari (MSY)}

Untuk menduga besaran MSY sumberdaya perikanan dan upaya penangkapan optimal, digunakan model Schaefer. Rumus-rumus untuk mencari potensi lestari (MSY) hanya berlaku bila parameter $b$ bernilai negatif, artinya untuk penambahan akan menyebabkan penurunan CPUE. Bila dalam perhitungan diperoleh nilai $b$ positif, maka perhitungan potensi dan upaya penangkapan optimum tidak dilanjutkan, tetapi hanya dapat disimpulkan bahwa penambahan masih memungkinkan untuk meningkatkan hasil tangkapan. Besarnya parameter a dan b secara matematik dapat menggunakan persamaan regresi sederhana dengan rumus:

$$
Y=a+b X
$$

Keterangan: Parameter a: intercept; Parameter b: Slope; y: Nilai variabel terikat (jumlah hasil tangkapan); x: Nilai variabel bebas (upaya penangkapan).

Selanjutnya parameter a dan b dengan rumus;

$$
\begin{gathered}
a=\frac{\left(\sum y \boldsymbol{i}\right)\left(\sum \boldsymbol{x} \boldsymbol{i}\right)-\left(\sum \boldsymbol{x} \boldsymbol{i}\right)\left(\sum \boldsymbol{x} \boldsymbol{i} \boldsymbol{y} \boldsymbol{i}\right)}{n \sum \boldsymbol{x} \boldsymbol{i}^{2}-\left(\sum \boldsymbol{x i}\right)^{2}} \\
b=\frac{n\left(\sum x i y i\right)-\left(\sum x i\right)\left(\sum y i\right)}{n\left(\sum x i^{2}\right)-\left(\sum x i\right)^{2}}
\end{gathered}
$$

Keterangan: x: Upaya penangkapan pada bulan; y: Hasil tangkapan per satuan upaya pada bulan; n: Jumlah sampel.

Setelah diketahui nilai a dan b, selanjutnya dapat ditentukan beberapa persamaan yang diperlukan (Rosana \& Prasita, 2015):
- Hubungan antara CPUE dengan upaya penangkapan (f);

$$
\text { CPUE }=a+b f
$$

- Hubungan antara hasil tangkapan (c) dengan upaya penangkapan (f) $\mathrm{c}=\mathrm{CPUE} \times \mathrm{f}$

$$
c=a f+b f 2
$$

Dari persamaan tersebut diperoleh model untuk menghitung hasil maksimum lestari (CMSY) dan upaya optimal $\left(\mathrm{f}_{\mathrm{opt}}\right)$ masing- masing sebagai berikut (Nugraha et al., 2012).

$$
\begin{aligned}
\text { CMSY } & =-a 2 / 4 b \\
\text { Fopt } & =-a / 2 b
\end{aligned}
$$

Keterangan: CMSY : Hasil tangkapan maksimum lestari; fopt: Jumlah upaya penangkapan optimal untuk mencapai MSY.

\subsubsection{Tingkat Pemanfaatan Sumberdaya Ikan}

Menurut Pauly (1983) dalam Sibagariang et al. (2014), persamaan dari tingkat pemanfaatan adalah sumberdaya ikan yang telah dimanfaatkan dihitung per periode waktu. Nilai persentase sumberdaya ikan yang telah dimanfaatkan dapat diketahui dengan rumus sebagai berikut:

$$
\mathrm{TPc}=\frac{\mathrm{Ci}}{\mathrm{MSY}} \times 100 \%
$$

Keterangan: TPc = Tingkat pemanfaatan pada periode ke-i (\%); $\mathrm{Ci}=$ Hasil tangkapan ikan pada periode ke-i (Kg); MSY = Maximum Sustainable Yield (Kg/Unit).

\subsubsection{Jumlah Tangkapan yang Diperoleh (JTB)}

Berdasarkan komitmen internasional yang diterbitkan FAO dalam Code of Conduct for Responsible Fisheries (CCRF), potensi sumberdaya laut yang boleh dimanfaatkan hanya sekitar $80 \%$ dari tingkat panen maksimum berkelanjutan (Maximum Sustainable Yield, MSY) (FAO, 2002). Jadi untuk menghitung JTB (Jumlah Tangkap yang diperbolehkan) menurut FAO (2002) yaitu dengan menggunakan rumus:

$$
\mathrm{JTB}=80 \% \times \mathrm{MSY}
$$

Jika JTB > MSY berarti terjadi overfishing tetapi jika JTB < MSY berarti penangkapan ikan masih bisa ditingkatkan untuk mendapatkan hasil yang lebih, tetapi tidak melebih MSY yang sudah ditetapkan.

\section{Hasil}

\subsection{Hasil Tangkapan}

Produksi hasil tangkapan merupakan hasil tangkapan nelayan di perairan Mapur, Kecamatan Bintan Pesisir selama sembilan bulan mengalami perubahan setiap bulannya. Data dari hasil tangkapan ikan delah di perairan Mapur selama sembilan bulan (Gambar 2). 


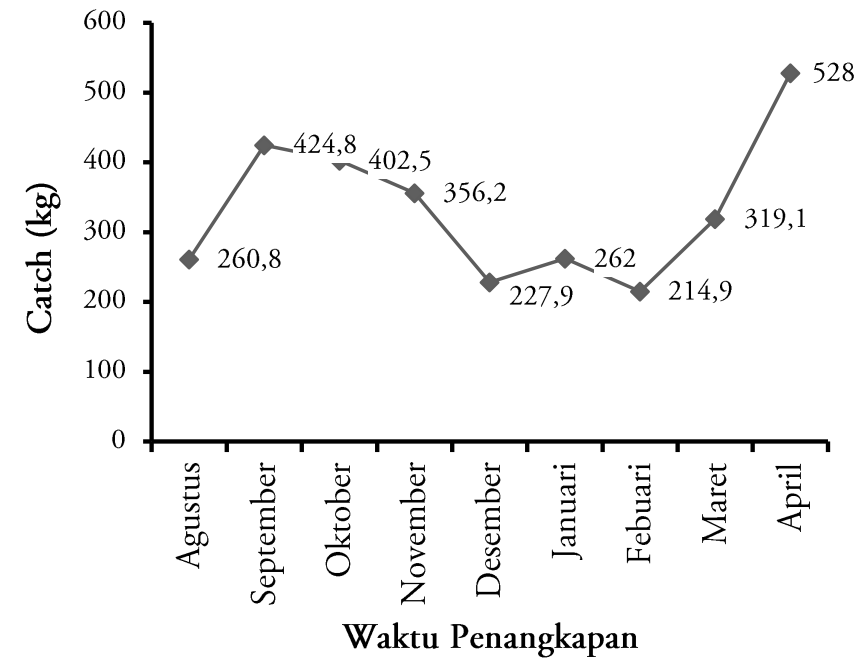

Gambar 2. Hasil tangkapan ikan delah di perairan Mapur, Kabupaten Bintan.

Berdasarkan Gambar 2, nilai catch (hasil tangkapan) selama bulan Agustus, September, Oktober, November, Desember, Januari, Februari, Maret, April serta Desember mengalami fluktuasi. Namun hasil tangkapan selama 9 bulan ini yang puncaknya yaitu bulan April sebesar $528 \mathrm{~kg} / \mathrm{bulan}$. Terlihat jelas pada bulan April terjadi hasil tangkapan optimal karena cuaca yang mendukung dan musim ikan delah. Apabila penangkapan berlangsung secara terusmenerus tanpa pengendalian dan pengelolaan maka kapasitas pertumbuhan populasi akan tetap menurun sehingga akan berbahaya terhadap kelestarian pupulasi sumberdaya tersebut (Piscandika et al., 2013).

\subsection{Upaya Tangkap}

Upaya penangkapan (banyak alat tangkap) merupakan salah satu faktor yang mempengaruhi hasil tangkapan nelayan ikan delah. Jumlah nelayan yang melakukan penangkapan di perairan Mapur yaitu 5 orang. Upaya penangkapan nelayan di Perairan Mapur dapat dilihat di pada Gambar 3.

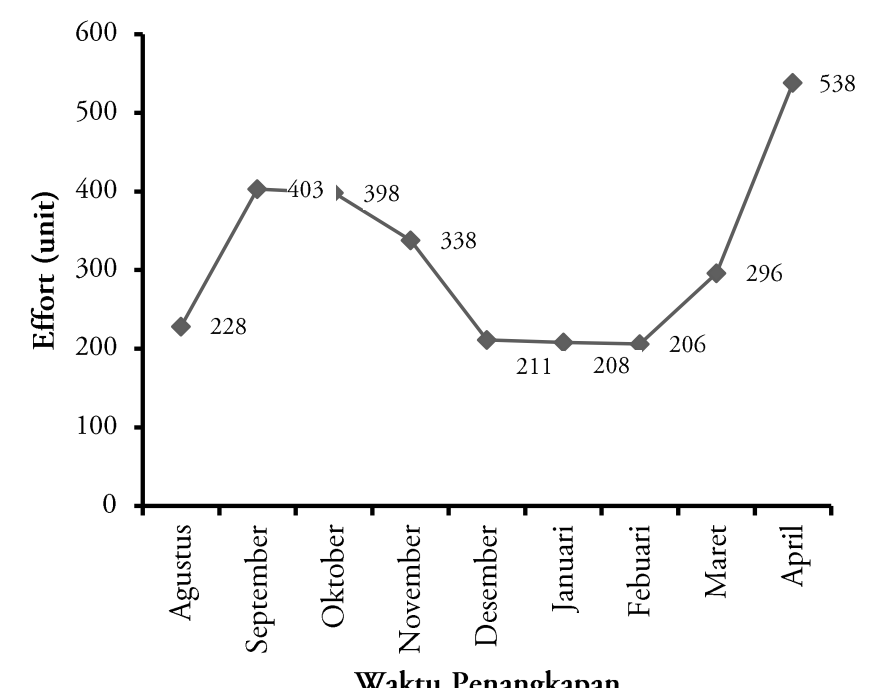

Gambar 3. Upaya Tangkapan ikan delah di perairan Mapur, Kabupaten Bintan.
Berdasarkan Gambar 3, upaya tangkap selama 9 bulan (Agustus, September, Oktober, November, Desember, Januari, Februari, Maret, April) yang telah dilakukan, diketahui upaya tangkapan fluktuatif. Terlihat upaya tangkapan optimal terjadi pada bulan April yaitu sebanyak 538 unit. Diduga hal ini terjadi karena faktor cuaca pada periode penangkapan tersebut sangat mendukung kegiatan penangkapan. Jika cuaca berubah menjadi ekstrim bisa mempengaruhi upaya tangkapan dilakukan nelayan. Sementara upaya tangkapan terendah terjadi pada bulan Desember. Diduga hal ini terjadi karena pada periode penangkapan tersebut terjadi angin utara atau angin kuat berdampak pada sulitnya kegiatan penangkapan dilakukan sehingga banyak nelayan tangkap ikan delah tidak melakukan penangkapan yang maksimal.

Hasil data upaya tangkap pada bulan Agustus sebesar 228 unit dengan hasil tangkapan sebesar 260,8 kg. Hasil tangkapan pada bulan September mengalami peningkatan menjadi sebesar $424,8 \mathrm{~kg}$. Peningkatan hasil tangkapan tersebut ditengarai dikarenakan upaya tangkapan meningkat menjadi sebesar 403 unit. Sedangkan pada bulan Oktober upaya tangkapan meningkat menjadi sebesar 398 unit tetapi hasil tangkapan menurun menjadi sebesar 402,5 kg. Penurunan hasil tangkapan dapat terkait dengan kondisi biologis ikan, seperti ikan yang ada di lokasi penangkapan belum beregenerasi namun dalam waktu hampir bersamaan sudah diambil dengan cara menambah alat tangkap. Regenerasi ikan delah relatif lambat dengan faktor kondisi hanya sekitar 0,6 per tahun (Prihatiningsih et al., 2018).

Pada bulan November dan Desember upaya tangkap diturunkan selama 2 bulan berturut-turut ternyata berpengaruh dengan hasil tangkapan juga yang menurun disebabkan oleh kondisi alam yang tidak memungkinkan nelayan untuk sering turun dan banyaknya kerusakan alat tangkap bubu yang dipengaruhi oleh angin kuat. Sedangkan pada bulan Februari upaya tangkap dinaikan dari bulan Desember namun tidak berpengaruh hasil tangkapan, oleh karen kegiatan penangkapan masih dipengaruhi oleh keadaan cuaca dan musim utara. Data hasil upaya tangkap pada bulan Maret-April meningkat turut mempengaruhi hasil tangkapan yang juga meningkat. Hal ini disebabkan oleh faktor keadaan alam atau cuaca mulai membaik dan faktor biologis ikan.

\subsection{Hubungan CPUE dan Effort Ikan Delah}

Nilai CPUPE menggambarkan keadaan suatu stok sumberdaya ikan yang ada di alam, sedangkan effort adalah upaya penengkapan terhadap suatu sumberdaya ikan (Sibagariang, 2014). Berdasarkan kurva hubungan CPUE dengan effort menunjukkan hubungan linier dengan nilai koefisien determinasi sebesar 46\%. Hubungan CPUE dan Effort ikan delah dapat dilihat pada Gambar 4. 


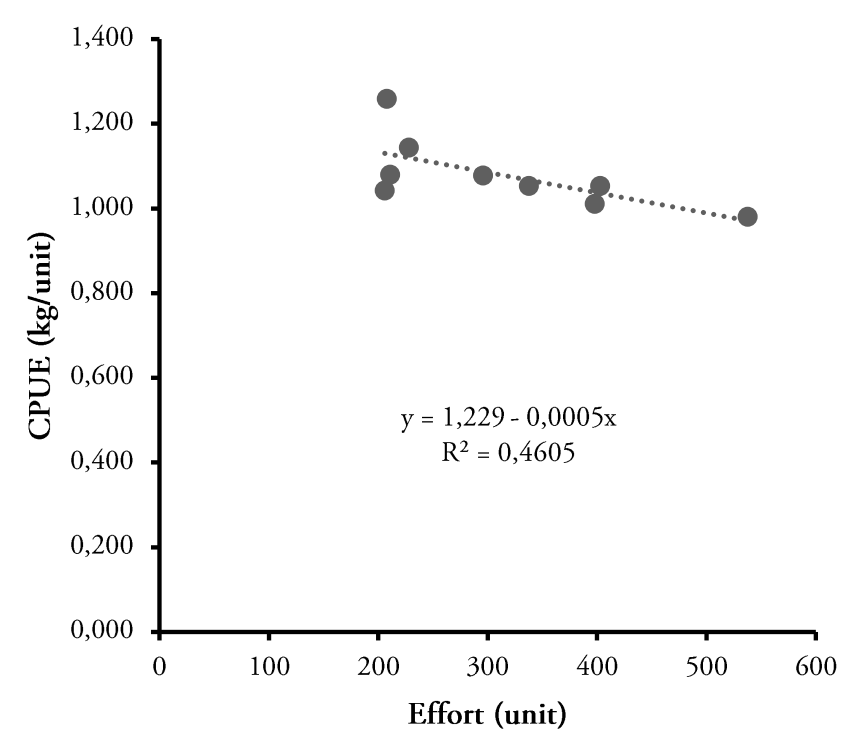

Gambar 4. Hubungan CPUE dan EFFORT penangkapan ikan delah di Perairan Mapur, Kabupan Bintan.

Berdasarkan Gambar 4, regresi linier yang berlaku pada produksi adalah $\mathrm{Y}=-0,0005 \mathrm{x}+1,229$ dan $\mathrm{R}^{2}=0,4605$. Berdasarkan persamaan regresi tersebut diketahui bahwa $46 \%$ penurunan produksi hasil tangkapan (y) disebabkan oleh upaya penangkapan (x). Sedangkan sebesar 54\% penurunan produksi hasil tangkapan (y) disebabkan oleh beberapa faktor seperti faktor alam dan faktor reproduksi biologi ikan delah.

Koefisien determinasi dengan simbol $\mathrm{R}^{2}$ digunakan sebagai indikator kecocokan suatu model. Nilai koefisien determinasi yaitu antara 0 sampai dengan 100\%. Dimanakan koefisien determinasi karena pada variasi yang terjadi dalam CPUE dapat dijelaskan oleh effort dengan adanya regresi linier $\mathrm{Y}$ atas X. Besarnya harga/nilai koefisien determinasi adalah berkisar $0 \leq R^{2} \leq 100$, artinya jika $R^{2}$ mendekati $100 \%$ maka dapat dikatakan pengaruh Effort terhadap CPUE adalah besar. Hubungan antara MSY dengan effort dapat dilihat pada Tabel 1.

Tabel 1. Pendugaan MSY dan Effort ikan delah di perairan Mapur, Kabupaten Bintan.

\begin{tabular}{lrl}
\hline \multicolumn{1}{c}{ Komponen Penilaian } & Model Scheafer & satuan \\
\hline a & 1,2290 & \\
b & $-0,0005$ & \\
MSY & 787,0673 & $\mathrm{~kg}$ \\
Fopt & 1280,7794 & $\mathrm{~kg} / \mathrm{unit}$ \\
\hline
\end{tabular}

\section{Pembahasan}

\subsection{Nilai Potensi (MSY)}

Nilai potensi lestari atau dikenal dengan istilah MSYmaximum sustainable yield merupakan suatu pendekatan perhitungan data potensi sumberdaya perikanan untuk mengetahui nilai pemanfaatan optimum terhadap sumberdaya perikanan. Nilai MSY diperlukan untuk menduga tingkat penangkapan yang dilakukan terhadap suatu sumberdaya perikanan. Berdasarkan hasil perhitungan analisis regresi linier antara upaya (effort) sebagai variabel $\mathrm{f}$ dan hasil tangkapan per upaya penangkapan (CPUE) sebagai variabel C, maka diperoleh nilai dugaan parameter intercept (a) dan slope (b) pada model Schaefer. Nilai intercept (a) dan $\mathrm{X}$ variabel (b) diperlukan untuk menduga nilai MSY dan Fopt dengan menggunakan model yang terpilih yaitu model Schaefer. Setelah nilai intercept (a) dan f variabel (b) diperoleh maka perhitungan selanjutnya dilakukan dengan mencari persamaan antara hubungan CPUE dengan effort pada model Schaefer (Simbolon et al., 2011). Hasil perhitungan nilai MSY penangkapan Ikan Delah di Desa Kelong disajikan seperti dapat dilihat pada Gambar 5.

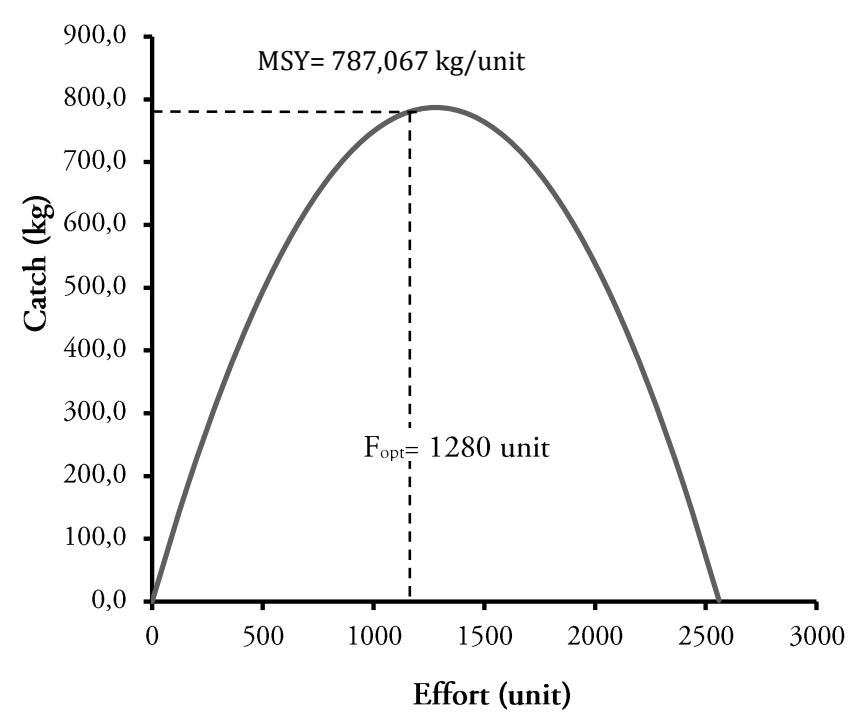

Gambar 5. Nilai MSY penangkapan ikan delah di perairan Mapur, Kabupaten Bintan.

Namun bagaimanapun, produksi ikan delah diperairan Mapur belum menujukkan ada gejala tangkap lebih (overfishing) tetapi penting dilakukan kajian yang lebih konprehensif agar dalam pengambilan keputusan peningkatan upaya penangkapan tidak mengarah pada gejala tangkap lebih dan penurunan hasil tangkapan. Berdasarkan Gambar 5, menunjukkan bahwa data produksi ikan delah dalam waktu 9 bulan terakhir (Agustus 2018-April 2019) dapat dihitung produksi lestari atau Maxsimum Sustainable Yield (MSY) dengan Metode Surplus produksi dari Model Schaefer dapat diketahui nilai potensial lestari serta upaya optimum ikan delah nilai diperairan mapur sehingga dapat ditentukan kapan terjadi overfishing dengan membandingkan upaya dan hasil tangkapan setiap bulan. Berdasarkan Model Schaefer, di dapat nilai upaya penangkapan optimum 1.280 alat tangkap per bulan dan nilai jumlah tangkapan maksimum sebesar 787,067 kg/unit.

Nilai MSY diatas nilai/optimum menunjukkan bahwa belum terjadi over eksploitasi. Menurut Rosana \& Prasita (2015), upaya optimum adalah upaya penangkapan yang dapat dilakukan oleh suatu unit penangkapan untuk mendapatkan hasil tangkapanyang optimal tanpa merusak kelestarian sumberdaya perikanan tersebut. Manfaat agar kerugian waktu, tenaga, dan biaya operasi penangkapan yang dilakukan diharapkan akan selalu mencapai hasil yang optimal. 


\subsection{Tingkat Pemanfaatan}

Rata-rata tingkat pemanfaatan ikan delah di Desa Kelong secara keseluruhan bahwa tingkat pemanfaatan pada selama 9 bulan sebesar 42\%, yang berarti hasil tangkapan berada pada ditingkat sedang. Tingkat pemanfaatan ikan delah tergolong sedang mencapai $42 \%$ dari nilai MSY, sehingga jika dilakukan penambahan upaya masih memungkinkan untuk mengoptimalkan hasil, tetapi tetap dikontrol dalam penangkapannya. Sesuai dengan pernyataan Piscandika et al. (2013) bahwa sumberdaya perikanan masih dikatakan underfishing jika pemanfaatannya masih dibawah nilai JTB (kurang dari $80 \%$ dari MSY).

Menurut Noija et al. (2014), pemanfaatan sumberdaya perikanan cukup potensial dan berpeluang untuk dikembangkan guna meningkatkan ekonomi masyarakat jika tingkat pemanfaatan masih rendah (dibawah nilai MSY). namun jika hasil tingkat pemanfaatan sudah tergolong tinggi, tidak boleh dilakukan peningkatan terhadap upaya karena akan berpotensi menjadi overfishing sebagai alternatif, agar peluang pemanfaat bisa di lakukan secara optimal yaitu dengan mengelola jumlah trip penangkapan dalam waktu yang lebih singkat dan penggunaan mesasize bubu dasar yang besar sehingga by catch berupa ikan-ikan kecil tidak tertangkap.

\subsection{Jumlah Tangkapan yang Diperbolehkan (JTB)}

Diketahui secara keseluruhan rata-rata sehingga jumlah tangkap yang diperbolehkan 80\% dari 787,067 yaitu sebesar $629,65 \mathrm{~kg} / \mathrm{unit}$. Artinya nilai hasil tangkapan masih dibawah JTB. Tangkapan masih boleh ditingkatkan lagi tetapi tidak melebihi batas MSY. Pengelolaan sumberdaya perikanan dengan pendekatan kuota penangkapan adalah upaya pembatasan jumlah yang boleh ditangkap. Untuk menjaga kelestarian suatu sumberdaya, maka nilai JTB harus di bawah maximum sustainable yield (MSY) yang telah ditentukan. Jumlah tangkap yang diperbolehkan (JTB) merupakan $80 \%$ jumlah tangkapan dari tingkat panen maksimum lestari.

Kesaulya et al. (2015) mengemukakan, bahwa dengan menunjukkan daerah operasi yang sangat terbatas, membuat intensitas penangkapannya tinggi yang mengakibatkan tekanan terhadap sumberdaya ikan sangat besar yang pada akhirnya terjadi penurunan hasil tangkapan. Untuk itu maka perlu adanya estimasi potensi yang tepat sebagai dasar kebijakan dalam pemanfaatan dan upaya pengelolaan.

\section{Simpulan}

Upaya penangkapan ikan delah pada Perairan Mapur yang Didaratkan di Desa Kelong pada bulan Agustus sampai bulan April belum mengalami overfishing dengan nilai potensi lestari maksimum (MSY) yaitu sebesar 787,067 $\mathrm{kg} /$ unit dengan upaya penangkapan optimal (f opt) 1.280 unit. Rata-rata tingkat pemanfaatan ikan delah di Perairan Mapur yang didaratkan di Desa Kelong dari bulan Agustus sampai April sebesar 42\% dari nilai MSY dikatagorikan sedang. Jumlah tangkapan yang diperbolehkan (JTB) ikan delah di Perairan Mapur yang didaratkan di Desa Kelong yaitu sebesar $629,65 \mathrm{~kg} / \mathrm{unit}$.

\section{Ucapan Terima Kasih}

Ucapan terima kasih disampaikan kepada abang Irwanto, bapak So Tong, Septian Eko Prasetyo, Fazraini Sihotang yang telah membantu dalam pengambilan data penelitian.

\section{Referensi}

Anonim, 2017. Profil Desa Kelong tahun 2017. Kecamatan Bintan Pesisir Kabupaten Bintan. Tidak dipublikasikan.

FAO. 2002. The State of World Fisheries and Aquaculture 2002. Food and Agriculture Organization. Rome. ISBN 92-5-104842-8.

Kesaulya T., Matrutty D.D.P., \& Uar M. F. 2015. Arah Penempatan Mulut Bubu Terhadap Hasil Tangkapan Ikan Di Perairan Dusun Mamua Kecamatan Leihitu Maluku Tengah. PSP Unpatti FPIK Unpatti-Ambon. Jurnal Amanisal 4(1): 24-31.

Mayu, Dersi H., Kurniawana., \& Arief F. 2018. Analisis Potensi dan Tingkat Pemanfaatan Sumberdaya Ikan di Perairan Kabupaten Bangka Selatan. Jurnal Perikanan Tangkap 2(1): 30-41.

Noija, D., Sulaeman M., Bambang M., \& A. A. Taurrusman. 2014. Potensi dan tingkat Pemanfaatan Sumbedaya Ikan Demersal diperairan Pulau Ambon-Provinsi Maluku. Jurnal Teknologi Perikanan dan Kelautan 5(1): 55-56.

Nugraha E., Koswara B., \& Yuniarti. 2012. Potensi Lestari dan Tingkat Pemanfaatan Ikan Kurisi (Nemipterus japonicus) Di Perairan Teluk Bintan. Jurnal Perikanan dan Kelautan 3(1): 91-98.

Pauly, D., A. Cabanban \& F.S.B. Torres, Jr. 1996. Some Simple Methods Assessment Tropical Fish Stocks. FAO Fisherise Technical. Philippines.

Piscandika, D, Efrizal, T, \& Zen, L, W. 2013. Potensi dan Tingkat Pemanfaatan Ikan Tongkol (Euthynnusaffinis dan Auxisthazard yang Didaratkan pada Tempat Pendaratan Ikan Desa Malang Rapat Kecamatan Gunung Kijang Kabupaten Bintan. [Skripsi] Fakultas Ilmu Kelautan dan Perikanan Universitias Maritim Raja Ali Haji. Tanjungpinang.

Prihatiningsi., Edrus, I.N., \& Sumiono, B. 2018. Biologi Reproduksi, Pertumbuhan dan Mortalitas Ikan Ekor Kuning (Caesio cuning Bloch,1791) diperairan Natuna. Bawal Widya riset Perikana Tangkap 10(1): 1-15.

Rosana, N. \& V.D. Prasita. 2015. Potensi dan Tingkat Pemanfaatan Ikan sebagai Dasar Perkembangan Sektor Perikanan di Selat Jawa Timur. Jurnal Kelautan 8(2): 72-73.

Sibagariang R. D’R., Mulya M. B., \& Desrita. 2014. Potensi, Tingkat Pemanfaatan dan Keberlanjutan Ikan Sebelah (Psettodes spp.) di Perairan Selat Malaka, Kabupaten Serdang Bedagai, Sumatera Utara. Jurnal Aquacoastmarine 5(4): 124-131.

Simbolon D., Wiryawan B., Wahyuningrum P.I., \& Wahyudi H. 2011. Tingkat Pemanfaatan dan Pola Musim Penangkapan Ikan Lemuru Di Perairan Selat Bali. Buletin PSP XIX (3): 293-307. 
Rapella Desiani, Department of Aquatic Resources Management, Faculty of Fisheries and Marine Sciences, Raja Ali Haji Maritime University. Jl. Politeknik Senggarang, Tanjung Pinang, Kepulauan Riau 29111, Indonesia. Email: rapelladesiani5@gmail.com

Susiana, Department of Aquatic Resources Management, Faculty of Fisheries and Marine Sciences, Raja Ali Haji Maritime University. Jl. Politeknik Senggarang, Tanjung Pinang, Kepulauan Riau 29111, Indonesia, Email: susiana@umrah.ac.id

URL ID-orcid: http://orcid.org/0000-0002-6792-0069

research-ID: http://www.researcherid.com/rid/E-7383-2017

URL Google Scholer: https://scholar.google.co.id/citations? user=HfXFCBMAAAAJ\&hl=id

URL Sinta Dikti: http://sinta2.ristekdikti.go.id/authors/detail?id=5972812\&view=overview

Febrianti Lestari, Department of Aquatic Resources Management, Faculty of Fisheries and Marine Sciences, Raja Ali Haji Maritime University. Jl. Politeknik Senggarang, Tanjung Pinang, Kepulauan Riau 29111, Indonesia. Email: febilestary@gmail.com

URL Google Scholer: https://scholar.google.co.id/citations?hl=id\&user=ltDRKugAAAAJ

URL Sinta Dikti: http://sinta2.ristekdikti.go.id/authors/detail/?id=6002698\&view=overview

\section{How to cite this article:}

Desiani, R., Susiana, \& Lestari, F. 2019. Utilization Rate of Yellow and blueback fusilier (Caesio teres) at Mapur Waters this fish landing on Kelong Village, Bintan Pesisir Sub district, Bintan Regency, Indonesia, Akuatikisle: Jurnal Akuakultur, Pesisir dan Pulau-Pulau Kecil, 3(2): 4955. DOI: https://dx.doi.org/10.29239/j.akuatikisle.3.2.49-55 